\title{
To make every pupil stronger, a curriculum in information and documentation in every French CDI
}

\author{
Valérie Glass \\ Magali Bon \\ FABDEN \\ 25, Rue Claude Tillier \\ 75012 Paris \\ France \\ valerie.glass@yahoo.fr
}

Keywords: FABDEN, France, Curriculum, School librarians association

\section{Introduction}

The FADBEN is the national association of professeurs documentalistes (teacher-librarians) in France. The professional association sees in the implementation of a curriculum in information and documentation the achievement of a triple convergence: first, epistemological, with the synthesis of information, media and digital literacies; secondly, professional, in contributing to the training and self-training of the professeurs documentalistes and thirdly operational, in programming the implementation of this teaching. This communication, divided into three parts, aims to show how this curriculum fits into the learning environment of the French school library. We will first explain the French context and then present the project of curriculum, with examples of teaching sessions integrated in this curriculum.

\section{French context}

\section{Background history}

The first school libraries appeared in 1958 in France but at that time they were called "services de documentation". In 1966 they became "services de documentation et d'information" (SDI) and the staff of those SDI was called "documentalists librarians". This denomination shows that the school library was only dedicated to reading and documentation in those days.

In 1972, the FADBEN was created and had a major role in the evolution of the profession, along with trade unions and the French Ministry of Education. In 1977 the first mission statement for our profession recognized the "mainly educational mission" of the school librarian. Then, during the 1980's, several texts were published by the Ministry of Education that recognized the specific role of the school librarians in the students' training, and particularly the second mission statement published in 1986, that is still in effect nowadays, which puts the students' training as a priority in the school librarians' missions. 
1989 marks an essential step in the evolution of our profession : a report attached to the Law on Education (Rapport annexé à la Loi n 89-486) acknowledged that "the high level of skill required by the technical and pedagogical tasks of school librarians makes it necessary to create an appropriate status for the position. Recruitment for the position needed to be done by a specific CAPES", a certificate of aptitude for secondary education. The same Law on Education requires the implementation of a Centre de Documentation et d'Information (CDI) in each secondary school.

However, in the years after the establishment of the CAPES, actively supported and encouraged by the FADBEN, the Mission Statement texts have not been updated, while educational issues as well as pedagogical practices have evolved. Since 1989, school librarians being recruited as teachers, have been called teacher librarians, "professeurs documentalistes". But if they officially belong to the teaching staff of the school, the professeurs documentalistes have not completely been considered as such by school administrators and other teachers who don't really know the missions and instructional resources which the professeurs documentalistes are in charge of.

In the 1990s, the FADBEN contributed to the thought on the foundations of information teaching, that is, how to develop students' abilities to access and to use information. The FADBEN began to highlight informational culture as content to develop in school. In 1997, the Association published a Référentiel de compétences informationnelles des élèves, a reference table of information literacy skills, to define a corpus of school knowledge in information and documentation. This work consisted of highlighting research skills to acquire, with different levels of control depending on the grade-level and age of the students, helping professeurs documentalistes to build pedagogical projects. The process for pedagogical projects starts from the definition of the objective of the research to the evaluation of the global process: questioning the topic, gathering information from accurate sources, creating and evaluating the final product.

In the early 2000's, the concept of curriculum in information and documentation appeared and several research groups were created. In 2007, in the FADBEN publication, Mediadoc, 64 ideas or concepts were established in a framework of seven main ideas (Information; Document; Indexation; Source; Informational space; Information research; Information usage), in order to help the professeurs documentalistes to formalize their teaching. The objective of this corpus is to provide instructional sessions that make students able to build knowledge. This corpus, hailed by the Ministry of Education in 2009, provides a progressive tool that serves to develop pedagogical projects. In 2010, the GRCDI (Research Group on Information Culture and Didactics) edited 12 propositions to develop a curriculum in information and documentation. Those propositions were used by the FADBEN to structure its curriculum.

In the "2013 July Act", the status of professeurs documentalistes as being part of teaching staff was reaffirmed in the "Référentiel des compétences professionnelles des métiers du professorat et de l'éducation" (Reference System attached to the teaching professions). Some specific skills related to professeurs documentalistes practice are listed there, in addition to the skills they share with all teachers. This text does not replace the 1986 Mission Statement, but it does introduce some changes. It first recalls that professeurs documentalistes are "full members of the teaching and educational team" with a specific skill 
to "create, implement and facilitate teaching and learning situations considering diversity of students". They "are responsible for the center of documentation and information, an area dedicated to training, reading, and access to culture and information", and they "contribute to the formation of all students in media and information literacy". As teachers, they can interact "directly with students in training and learning activities from their own initiative or according to the needs expressed by teachers in a discipline".

\section{Current issues}

The professeurs documentalistes aim at making students, future citizens, independent and responsible in informational, media and digital environments. Indeed students need new skills and knowledge in today's information-based society. They need to develop scientific knowledge to acquire a culture of information. That's why information didactics is needed. And that's why the FADBEN defends the idea of a curriculum information and documentation to follow the recommendations of the research groups.

New additions related to teacher librarian duties in the "2013 July Act" confirmed the political will of a specific teaching mission given to them. Indeed, in the part called « Learning with digital technology », it is written that the professeurs documentalistes must « be fully concerned and involved in the learnings related to digital technology». This " 2013 July Act » met the claims the FADBEN has expressed since 1989 and give a real value to the work developed by our association since 1997. It also gives us an impetus to go further and confirms the necessity to develop a curriculum in information and documentation.

\section{Curriculum and Wikinotions}

The lack of a learnings progression in most French school libraries is the point of the elaboration of a curriculum in information and documentation. For most of French teacherlibrarians it's not possible to teach in every classes of each grade, either middle or high school. Most of the time teacher-librarians focus their teaching time on the first grade of the middle school. There is a real difference in information and documentation knowledge between students depending on each school.

That's why the need of information and media literacy leads the FADBEN's work towards establishing the standard of a curriculum in information and documentation. This work is reflected, firstly, in a collaborative platform called InfoDoc Wikinotions, and secondly, in an attempt at writing the curriculum.

The FADBEN calls for the implementation of a curriculum in information and documentation that defines the concepts to be transmitted and that determines their implementation in a progression of learnings, along with their evaluation. The professional association is convinced of the necessity of this progressive learning as a logic of a discovery, an initiation and a thorough analysis, for a true acquisition of knowledge and skills by the students.

Formalizing a curriculum in information and documentation should also help to promote the acquisition of a professional culture because this plan deals with pedagogical approaches, as well as activities and instructional reference objects or different forms of assessment knowledge. It may also be the occasion of an important time to share practices, and to gain from each other's teaching models and methods.

The FADBEN's curriculum proposals are based on practical knowledge as well as theories that have already been developed in the field of information and communication sciences 
research. The foundations of such a curriculum were initiated in 2003. Since then, discussions have carried on. In 2010, the contribution of the GRCDI, Research Group on information literacy and information didactics, clearly provided a curriculum, specifically from twelve proposals. The existence of a curriculum in information and documentation requires constructing a catalogue of references and resources constituting the curriculum, to carry on the reflection about the specific notions.

This work has a new impetus with the FADBEN Info-Doc Wikinotions, a collaborative platform in which academic and school teachers are invited to participate. This project aims at updating the corpus of knowledge, assembling educational activities, as well as providing an exhaustive list of scientific and professional references on the subject. These references can develop definitions of concepts considered as essential, definitions for students rather than professionals, in order to facilitate the educational and pedagogical work of teacherlibrarians. For each concept, there are a number of features with a beginner level and an advanced level.

It seems important also to observe existing practices of professeurs documentalistes, and to compare them with the research field and observations on students' psychological and cognitive development. This reflective work on theory and practice allows us to identify on which level a discovery can be initiated or developed, or whatever specific notion, in relation to specific knowledge or skills in information and documentation. If we consider that the concepts of document and document structure can be developed very early, starting with teaching resources in educational situations of student activity, it is estimated that the concepts of classification, publication of the information economy can wait to be developed later on, as well as the concepts of catalog, editorial content, documentary instability. This reflection is accompanied by an interest in regarding the actual work of teacher-librarians: especially when pedagogical sequences which explain different notions are published on the Internet.

Then, to improve the current situation and identify rich collaborations and complementarities, we rely on existing curriculum, from kindergarten to high school, with programs that are about to be revised in the 2015 French context of a school reform. This examination of existing programs consists of identifying the specific elements of information and documentation in these texts, and also in beginning to understand the integration of a specific instruction in a new global curriculum.

From these elements, we should be able to provide programming, from the basic concepts of information and documentation in middle and high school, with considerations on organization and evaluation of the learning. The program is built around four fields. In each field, we do note the objectives set for the level, then the concepts developed, as part of a discovery, an initiation or thorough analysis:

- Informational and digital environments

- Process of information and documentation

- Critical distance on the media, ICT and information

- Legal and ethical responsibility on the information 
For each level, in each field, the question is to explain the objectives, as well as the concepts and the skills that are associated with these objectives, without forgetting comments suggested with the associated activities.

This work developed from a programmatic framework, identifying the progression of the curriculum in information-documentation, in secondary schools and high schools, including a number of competencies to achieve, that are related to the essential ideas; this general knowledge is given through different pedagogical approaches.

\section{Examples of learning sessions}

The pedagogical role of the professeurs documentalistes is to help pupils to master the tools provided by the school library, and so, to develop a rational control, with critical thinking about tools and about media and information. French professeurs documentalistes are specifically trained to teach and to implement learning sessions associated with the educational contents of the information, documentation, with a specific role in teaching medias and new medias.

We will show now some examples of learning sessions on different themes and at different grades.

Example of a course on "digital identity" with pupils in the second year of secondary school in France (about 12-13 years old)

The objectives of this instructional session are:

- Making the pupils realize that all they do on Internet leaves traces

- Giving them keys to keep their digital identity under control

This teaching session can be integrated to the curriculum in civics, which is a school subject in France. Indeed, in the curriculum of civics in that grade-level, there is a chapter called "Identity and the identities".

Since we address students who are about 12-13 years old, we should refer to the beginner level definition of digital identity proposed by the Wikinotions, which is :

All the features that define an individual on the basis of the elements that one can find about him or her on Internet.

Here are some examples we can give to students to explain the notion

Digital identity refers to:

All the information available on a Facebook profile

- the analysis of one person's tweets

- all the digital profiles of one individual on the social networks

And as counterexample, we can give:

- a physical identity or a real identity

- a civil identity

Example of a course on "the evaluation of information on Internet" with students in the fourth year of secondary school in France (about 14-15 years old) 
This teaching session can be integrated to any part of a curriculum but the one we present here is a collaboration with the teacher of SVT (natural sciences). Indeed, in this grade-level, the students have to write a paper and give a talk on a scientific subject. This work runs on 4 to 5 months and students they have to search information of course. They do this work in autonomy but at least 2 sessions can take place with the teacher-librarian : the first one to launch the project : brainstorming / subject analysis (= defining information needs) and the second one to learn how to assess the reliability of websites. This is this second session we are going to present here.

So the main objective of this session is to learn how to ass information reliability. Since we address students who are about 14-15 years old, we can refer to the advanced level definition of "information assessment" proposed by the Wikinotions, which is :

The evaluation of information consists of assigning a value to information, with personal criteria of assessment. It is based on a comparative study of the sources, and it varies from one person to the other.

If we refer to the Wikinotions, here are some examples we can give to students to explain the notion

The evaluation of information is:

- To make the founded information correspond to the information need

- To search the author of a document and his/her authority

- To compare several information on the same subject.

As counterexamples, we can give:

- To take an information up as it is, without checking it

- To forget crossing one's information sources (when one makes a critical reading)

In the teaching session we present to you, we first teach the students how to analyze an URL in order to choose the accurate website in the results of a search engine, then we explain the difference between the relevance of information (it corresponds with my information need) and the reliability of information (its author is reliable or credible). We explain them that an information can be relevant but unreliable and, conversely, an information which is reliable may not be interesting for us because it isn't relevant. Finally, we teach them how to assess the credibility of a relevant information by making them use the Quintilien questionnaire.

In the Wikinotion, we can choose here the beginner level definition of the relevance of information, which is :

Relevance is one criterion of the evaluation of information. It is bound to the information need and is useful to select an information which enables to answer a question that was asked during an information search. A relevant information is an information that one can understand and use.

The teacher librarian can evaluate this teaching session immediately by asking the students to compare 3 given websites on a much debated subject (for ex. the GMO). There can also be a later or mid-term evaluation : when the students give their global work back, they have 
to fill in a table in which they must analyze 2 websites they've used or just found during their information research.

\section{Conclusion}

The FADBEN aspires to the formalization of a curriculum in information and documentation in order to give to the professeurs documentalistes the capability of implementing their teaching and enabling students to acquire information, media and digital knowledge and skills. A first realization attempt of this work is in this publication, written in French, under the title "Vers un curriculum en information-documentation" and published at the end of 2014.

The FADBEN wants to share its thoughts and works with national or international stakeholders to bring a reality to its project within an unlimited timetable. The FADBEN wants to carry on the work to which it has been committed since 2003. The FADBEN is dedicated to formalizing a new stage in the realization of this kind of curriculum with tangible proposals stressing theoretical and pedagogical reflections, as well as evolutionary and experimental practice, in educational terms.

2015 Is a very important year as French Ministry of Education is working to create new curricula for the secondary schools. The FADBEN has met minister's advisers several times to speak about the status of our profession and the educational contents we could be in charge of. Let's hope the reflections and work of our association will be taken into account and that the specific educational contents relating to digital, media and information literacies will be at last officialized.

\section{References}

In 2006 : the ERTé (Equipe de Recherche en Technologie éducative) « Culture informationnelle et curriculum documentaire » (with P. Duplessis)

In 2007 : Création du GRCDI (Groupe de Recherche sur la Culture et la Didactique de I'Information) 